\title{
Predictors of trauma in bank employee robbery victims
}

\author{
This article was published in the following Dove Press journal: \\ Neuropsychiatric Disease and Treatment \\ 7 October 2015 \\ Number of times this article has been viewed
}

\author{
Nicola Mucci' \\ Gabriele Giorgi² \\ Javier Fiz Perez ${ }^{2}$ \\ Ivo lavicoli' \\ Giulio Arcangeli ${ }^{3}$ \\ 'Institute of Public Health, Catholic \\ University of Sacred Heart, Rome, \\ Italy; ${ }^{2}$ Department of Psychology, \\ European University of Rome, Rome, \\ Italy; ${ }^{3}$ Department of Clinical and \\ Experimental Medicine, University \\ of Florence, Florence, Italy
}

\begin{abstract}
In the literature, there are many studies that have investigated the psychological reactions resulting from traumatic events of varying degrees, such as wars, natural disasters, and acts of violence. Few, however, are the searches performed on employees who are victims of robbery. We carried out a research to assess the psychological reactions of 644 bank employees who had been victims of robbery, especially with regard to the possible development of posttraumatic stress disorder (PTSD). The aim of this study was to evaluate the variables pre-, peri-, and postrobbery trauma in relation to the development of psychopathological symptoms. The exploration of the reactions after the robbery was carried out on 644 employees of a banking institution, present throughout the national territory, through a survey, consisting of a general description of the event, the Impact of Event Scale Revised-6 scale, and the General Health Questionnaire-12, during the days after the robbery. The analysis showed that the development of pretrauma variables is not significant and that peritrauma variables are partially significant. In particular, being directly involved in the robbery, the thought of being hurt, and the feeling of intense fear are associated with posttraumatic symptoms. Finally, among the posttrauma variables, anxiety and depression played a major role. Surprisingly, a lower level of self-confidence seems to be related negatively to the PTSD symptomatology.
\end{abstract}

Keywords: bank, bank robbery, occupational health, workplace, stress, PTSD

\section{Introduction}

The issue of bank robberies, in their different aspects, is an object of attention of the banking sector and its institutions; however, a positive trend in terms of prevention has not emerged in recent years. According to the "Report on Robberies in Bank Branches in 2012", published by the Research Centre for Anti-crime Security of the Italian Banking Association, since 2007 bank robberies have more than halved (approximately $63 \%$ ). ${ }^{1}$ Despite this positive development, the consequences for the staff involved in a criminal event such as a robbery remain of major concern to banks. Risk management in robberies has gradually become one of the main issues of health and safety at work, to be assessed in accordance with the principles and rules laid down by the legislation for prevention. The spirit of the consolidated law for the protection of health and safety in the workplace (Legislative Decree No 81/2008 and Subsequent Amendments) is not to protect the bank's assets, but to make the employer eliminate or minimize the risks to which employees are exposed as a result of a criminal event. Indeed, the legislature assigns the employer the responsibility of protecting employees, not from general risk, namely, that any person may be exposed to an event since they are part of the community, but as a specific risk, since it is connected to the type of work. ${ }^{2}$ The Italian National Institute for Insurance against Accidents at Work believed that because of the goal of the Legislative Decree No 81/2008 and Subsequent Amendments, the "risk
Correspondence: Giulio Arcangeli Department of Clinical and Experimental Medicine, University of Florence, $\mathrm{I} / 23$, Largo Piero Palagi, I-50I39 Florence, Italy Tel +39055 417769

Fax +39055 7948 I30

Email giulio.arcangeli@unifi.it
Neuropsychiatric Disease and Treatment 2015:II 2605-26/2

Dovepress

http://dx.doi.org// 0.2147/NDT.S88836 (c) (i) (9) 2015 Mucci et al. This work is published by Dove Medical Press Limited, and licensed under Creative Commons Attribution - Non Commercial (unported, v3.0) License. The full terms of the License are available at http://creativecommons.org/licenses/by-nc/3.0/. Non-commercial uses of the work are permitted without any further permission from Dove Medical Press Limited, provided the work is properly attributed. Permissions beyond the scope of the License are administered by Dove Medical Press Limited. Information on how to request permission may be found at: http://www.dovepress.com/permissions.php 
of robbery" should be included under occupational hazards and be properly assessed. ${ }^{3}$

As a traumatic event, a robbery may have consequences on both the physical and psychological integrity of the employees involved. Compared to the past, we now see an almost total absence of ill treatment of staff by the robbers. A survey carried out by several banks pointed out that nobody needed to seek medical attention, even after suffering violence, and that, in the few cases that required it, any injuries found resolution after a few days. ${ }^{4}$

Psychological consequences are, however, a different matter. According to the scientific literature on the subject, it is clear that the response to traumatic events is the result of a complex interaction of many variables, which include the type of stressful event, the individual characteristics, the subjective response, and social support to which one has access. ${ }^{5-7}$ People's reactions to critical events can be varied, and the psychological consequences can be just as varied. ${ }^{8}$ If, for example, the victim of the robbery is experiencing a negative emotional state (going through mourning, separation, health problems, etc), it is easy to understand that there may be a greater impact from a critical event. The reactions after the traumatic event may resolve spontaneously, especially if favorable conditions are present and other traumatic events do not arise. However, in some cases, it is possible that the reactions evolve toward more complex clinical pictures. One can pass from an acute stress disorder (ADS) to a posttraumatic stress disorder (PTSD). ADS occurs within 4 weeks of stress and lasts from a minimum of 2 days to a maximum of 4 weeks; it represents the preliminary category of PTSD and is characterized by dissociative symptoms listed in the DSM-IV (intrusion symptoms, avoidance, and hyperactivity). According to the DSM-IV diagnosis of PTSD, certain criteria must be met. ${ }^{9}$ First, the person must have been exposed to a traumatic event (which has resulted in death or threat of death or serious injury or threat of physical integrity to self or others) and the response of the subject must have been one of intense fear, horror, or feelings of helplessness. Psychopathological symptoms (intrusion, avoidance, and arousal) must also arise, resulting in clinically significant distress or impairment in social, occupational, or otherwise important areas. Finally, the disorder must last more than 1 month. Depending on the duration of the disorder, we can define PTSD as: acute PTSD, if symptoms last less than 3 months; chronic PTSD, if symptoms last longer than 3 months; delayed-onset PTSD, if symptoms occur at least 6 months after the event. ${ }^{10,11}$
The predictors of PTSD are pre-, peri-, and posttrauma variables. Pretraumatic factors are the individual characteristics of the subject: the female sex, age less than 25 years, a low level of education, having experienced traumatic events in the past, and the presence of preexisting psychopathological disorders are all factors favoring the onset of PTSD. ${ }^{11,12}$ However, several studies have confirmed a strong association of posttraumatic syndromes with poorer mental health and with psychological problems such as depression, anxiety, and personality disorders. ${ }^{13,14}$ As far as demographic data are concerned, its association appears less solid. For instance, in a sample of robberies, Miller-Burke et $\mathrm{al}^{5}$ did not find a significant relationship of age and sex with the development of posttraumatic symptoms. Accordingly, Ozer et al's ${ }^{15}$ meta-analysis investigating pretrauma variables concluded in pointing out the marginal effect of these specific variables in understanding the development of PTSD.

Peritraumatic risk factors are those closely related to the event: duration, intensity, and nature of the traumatic event. Literature found a strong association between perceived life threat and posttraumatic symptomatology, both in victims of robberies and in victims of other types of assaults and aggressions. ${ }^{12,15,16}$ For instance, believing they or someone else could be harmed, feeling threatened by the robber, and seeing a weapon might increase the risk of developing PTSD. ${ }^{6,16}$

In addition, literature found relationships between PTSD and perceived helplessness, since traumatized employees seem to commonly feel helpless or fearful during the robbery. In addition, proximity to the robber (such as seeing the robbery, being in the same room with the robber, and being able to identify the robber) has been found to be associated with posttraumatic symptoms following robbery. ${ }^{12,14}$

Finally, the posttraumatic factors are the immediate reactions after the trauma, such as the consequences of physical or psychological damage or loss. ${ }^{17,18}$

It is important to insist on the destabilizing effects that a robbery can have on a person with a nonoptimal mental health. It is noteworthy that trauma itself overwhelms the normal systems that we use to deal with unfortunate events by assigning them some meaning. The defense system, when facing the impossibility of reacting properly, implements alternative mechanisms such as "avoidance", which includes avoiding any activity or thought associated with the trauma. This is an example of a mechanism that a person with suboptimal mental health would have a hard time exploiting. Indeed, these subjects appear to be more prone to develop PTSD. Furthermore, in many chronic cases of PTSD, we can observe 
the occurrence of other conditions, which leads to diagnostic issues, due to the overlapping medical symptoms. There is a documented comorbidity between PTSD and depression. Numerous studies have shown that a history of psychiatric disorders or a preexisting tendency to anxiety or depression can all be vulnerability factors for PTSD. ${ }^{4,17,19}$

\section{Aim}

The main aim of this research is to analyze the association of pre-, peri-, and posttrauma variables, measured a few days after the robbery, and the development of PTSD symptoms. In particular, we want to test whether exposure to the robbery, the traumatic event, may contribute to the onset of typical symptoms of PTSD: intrusion, avoidance, and arousal. According to the relevant literature, we expect that the severity of posttraumatic symptoms present positive and significant association with young age, female sex, previous trauma, robberies in the past, perceived danger of life, perception of lack of aid, and proximity to the robber. In addition, we expect that posttraumatic experience, such as the development of mental health problems, can have a positive association with the severity of posttraumatic symptoms.

\section{Methods Questionnaire}

Written consent was obtained from participants for the use of their information in this medical study. The exploration of the victims' reactions after the robbery was carried out in the days immediately following the robbery (1-7 days) and featured a questionnaire administered by occupational physicians to the people involved in the robbery or to those who had explicitly requested it. The administration of the questionnaire and the results obtained were maintained with professional secrecy and general respect of privacy. The survey consists of three parts. The first part consists of demographics (pretrauma variables) and several questions (yes/no) describing the event in general, which represent the peritrauma variables:

1) Whether he/she was involved directly in the robbery or was just an observer.

2) Whether he/she were previously victims of a robbery.

3) Whether he/she was in the same room as the robber.

4) Whether he/she felt threatened by the robber.

5) Whether he/she imagined being potentially harmed.

6) Whether he/she felt intense fear.

7) Whether he/she had physical contact with the robber.

The second part featured the Italian version of the Impact of Event Scale Revised-6 (IES-R of six items), which investigates the mental and behavioral reactions to a traumatic event and analyses the specific symptoms: intrusion, avoidance, and hyperarousal. ${ }^{20,21}$ The respondents of the questionnaire are invited to indicate - on a four point scale ranging from never (score 1) to often (score 4) - how frequently each symptom was experienced in the previous week.

The third part consists of the General Health Questionnaire (GHQ12). The GHQ12 is one of the most recognized tools within the scientific community for the measurement and assessment of mental health. ${ }^{22,23}$ A four point Likertscale scoring method was used according to the alternative responses presented to participants: $(0=$ "less than usual"; $1=$ "no more than usual"; 2 = "rather more than usual"; and $3=$ "much more than usual"). Thus, the questionnaire gives a total score ranging from 0 to 36 points, in which a higher score indicates mental health problems. The questionnaire was used for measurement of posttraumatic variables.

\section{Sample}

The survey, which took place between 2012 and 2014, involved 644 employees of a banking institution on Italian territory. The sample consisted of 276 females $(43 \%, n=644)$ and 368 males $(57 \%, n=644)$, with a mean age of $41.4 \pm 9.7$ years. The questionnaires were collected from various Italian regions with the following geographical distribution: 271 from the north of Italy, 42\% $(n=644), 188$ from central Italy, 29\% $(n=644)$, and 185 from the south of Italy, 29\% $(n=644)$. There were 15 regions involved: Lombardy (137), Piedmont (29), Veneto (30), Friuli-Julian Venetia (5), and Emilia-Romagna (70) from the north of Italy; Tuscany (57), Umbria (22), Marche (10), Abruzzo (26), and Latium (73) from central Italy; Sicily (140), Calabria (8), Apulia (10), Campania (20), Basilicata (6), and Sardinia (1) to the south, and the islands of Italy.

The questionnaires were delivered, in respect of anonymity and privacy, to a consortium formed by occupational medicine and occupational psychology specialists, who proceeded to analyze them using appropriate statistical methods (descriptive statistics, Pearson's $r$ correlation, and hierarchical regressions).

\section{Analyses}

Statistical analyses were performed to identify the existence of relations between the variables investigated, according to the literature. ${ }^{5,12}$ In particular, hierarchical regression was used to evaluate the relationship between a set of independent variables and the dependent variable, controlling for or taking into account the impact of a different set of independent variables on the dependent variable. 
Table I Correlations among the variables

\begin{tabular}{|c|c|c|c|c|c|c|c|c|c|c|c|c|c|c|c|}
\hline Variable & I & 2 & 3 & 4 & 5 & 6 & 7 & 8 & 9 & 10 & II & 12 & 13 & 14 & 15 \\
\hline $\begin{array}{l}\text { I Involvement in } \\
\text { the robbery }\end{array}$ & - & -0.04 & $0.48 * *$ & $0.40 * *$ & $0.13 * *$ & $0.19 * *$ & $0.25 * *$ & $-0.11 * *$ & $-0.18 * *$ & $-0.12 * *$ & $-0.17 * *$ & $-0.20 * *$ & $-0.18 * *$ & $-0.24 * *$ & $-0.24 * *$ \\
\hline $\begin{array}{l}2 \text { Being already } \\
\text { robbed }\end{array}$ & & - & -0.01 & 0.00 & 0.02 & 0.00 & -0.01 & 0.07 & 0.00 & 0.01 & 0.02 & 0.00 & 0.01 & 0.04 & 0.00 \\
\hline $\begin{array}{l}3 \text { Being in the same } \\
\text { room of robber }\end{array}$ & & & - & $0.31 * *$ & 0.02 & $0.09 *$ & $0.21 * *$ & -0.06 & -0.06 & $-0.10^{*}$ & $-0.10^{*}$ & $-0.12 * *$ & $0.08^{*}$ & $-0.14 * *$ & $-0.13 * *$ \\
\hline $\begin{array}{l}4 \text { Being threatened } \\
\text { by the robber }\end{array}$ & & & & - & $0.25 * *$ & $0.35^{* *}$ & $0.25 * *$ & $-0.14 * *$ & $-0.24^{* *}$ & $-0.16^{* *}$ & $-0.23 * *$ & $-0.21^{* *}$ & $-0.23 * *$ & $-0.26 * *$ & $-0.27^{* *}$ \\
\hline $\begin{array}{l}5 \text { Being subject of } \\
\text { potential injuries }\end{array}$ & & & & & - & $0.33^{* *}$ & $0.14 * *$ & $-0.13^{* *}$ & $-0.25^{* *}$ & $-0.22 * *$ & $-0.26 * *$ & $-0.25 * *$ & $-0.27^{* *}$ & $-0.35^{* *}$ & $-0.33 * *$ \\
\hline $\begin{array}{l}6 \text { Experiencing an } \\
\text { intense fear }\end{array}$ & & & & & & - & $0.12 * *$ & $-0.16^{* *}$ & $-0.38^{* *}$ & $-0.26 * *$ & $-0.35^{* *}$ & $-0.38 * *$ & $-0.44 * *$ & $-0.44 * *$ & $-0.48 * *$ \\
\hline $\begin{array}{l}7 \text { Having a physical } \\
\text { contact with the } \\
\text { robber }\end{array}$ & & & & & & & - & 0.06 & $-0.14 * *$ & -0.07 & $-0.12 * *$ & $-0.13^{* *}$ & $-0.09 *$ & $-0.09 *$ & $-0.12 * *$ \\
\hline 8 Loss of confidence & & & & & & & & - & $0.53 * *$ & $0.44 * *$ & $0.66 * *$ & $0.27 * *$ & $0.34 * *$ & $0.27 * *$ & $0.34 * *$ \\
\hline 9 Anxiety & & & & & & & & & - & $0.62 * *$ & $0.91 * *$ & $0.50 * *$ & $0.70 * *$ & $0.60 * *$ & $0.69 * *$ \\
\hline 10 Dysphoria & & & & & & & & & & - & $0.86 * *$ & $0.32 * *$ & $0.53 * *$ & $0.41 * *$ & $0.49 * *$ \\
\hline II GHQ-I2 & & & & & & & & & & & - & $0.47 * *$ & $0.68 * *$ & $0.56 * *$ & $0.66 * *$ \\
\hline 12 Avoidance & & & & & & & & & & & & - & $0.60 * *$ & $0.60 * *$ & $0.83 * *$ \\
\hline 13 Arousal & & & & & & & & & & & & & - & $0.70 * *$ & $0.88 * *$ \\
\hline 14 Intrusion & & & & & & & & & & & & & & - & $0.88 * *$ \\
\hline 15 IES-R-6 & & & & & & & & & & & & & & & - \\
\hline
\end{tabular}

Notes: $* P \leq 0.05 ; * * P \leq 0.01$.

Abbreviations: GHQ-12, General Health Questionnaire-I2; IES-R-6, Impact of Event Scale Revised-6.

First descriptives and correlations were calculated between the variables (Table 1).

Second, we calculated hierarchical regression analysis. In the first analysis, the impact of IES-R-6 total score was the dependent variable. In the first block, the demographic variables (sex and age) were tested as predictors, while, in the further blocks, dimensions of peritrauma variables were tested: proximity/familiarity with the robbery as the second block and perceived fear of harm and helplessness as the third block. Finally, posttrauma variables (mental health problems measured by the GHQ-12) were added in the fourth block. Further analysis tested intrusion, avoidance, and hyperarousal. Instead of using the total score of the IES-R-6, we used its subscales. Tables 2-5 list the results of the four regression analyses.

Table 2 Hierarchical regression with IES-R-6 as criterion variable

\begin{tabular}{lllll}
\hline Predictors & IES-R-6 & & Block 3 \\
\cline { 2 - 5 } & Block I & Block 2 & 0.00 & Block 4 \\
\hline Age & 0.00 & 0.00 & 0.03 & 0.03 \\
Sex & 0.02 & 0.05 & $-0.1 I^{*}$ & 0.00 \\
Involvement in the robbery & - & $-0.22^{* * *}$ & 0.00 & $-0.07^{*}$ \\
Being already robbed & - & 0.00 & -0.02 & 0.00 \\
Being in the same room of robber & - & -0.02 & -0.03 & -0.03 \\
Being threatened by the robber & - & - & $-0.18^{* * *}$ & -0.00 \\
Being subject of potential injuries & - & - & $-0.38^{* * *}$ & $-0.11^{*}$ \\
Experiencing an intense fear & - & - & 0.00 & $-0.21^{* * *}$ \\
Having a physical contact with the robber & - & - & - & -0.02 \\
Loss of confidence & - & - & - & $0.55^{* *}$ \\
Anxiety & - & - & $0.27^{* * *}$ \\
Dysphoria & - & $0.05^{* * *}$ & $0.22^{* * *}$ \\
$R^{2}$ & 0.00 & $0.05^{* * *}$ & $0.55^{* * *}$ \\
$\Delta R^{2}$ & - & $-28^{* * * *}$ \\
\hline
\end{tabular}

Notes: $* P<0.05 ; * * P<0.01 ; * * * P<0.001 . R^{2}$ is coefficient of determination. $\Delta R^{2}$ is the change in $R^{2}$ values from one model to another. Variables tested as predictors in the blocks: Block I, pretrauma (demographics); Block 2, peritrauma (proximity/familiarity with the robbery); Block 3, peritrauma (perceived fear of harm and helplessness); Block 4, posttrauma (mental health problems measured by the GHQ-12).

Abbreviations: GHQ-12, General Health Questionnaire-12; IES-R-6, Impact of Event Scale Revised-6. 
Table 3 Hierarchical regression with avoidance as criterion variable

\begin{tabular}{lllll}
\hline Predictors & Avoidance & & \\
\cline { 2 - 4 } & Block I & Block 2 & Block 3 & Block 4 \\
\hline Age & 0.00 & 0.00 & 0.01 & -0.01 \\
Sex & 0.01 & 0.02 & $-0.09^{*}$ & -0.03 \\
Involvement in the robbery & - & $-0.18^{* * *}$ & -0.06 \\
Being already robbed & - & -0.01 & -0.0 .03 & -0.01 \\
Being in the same room of robber & - & -0.03 & -0.01 & -0.04 \\
Being threatened by the robber & - & - & $-0.13^{* *}$ & -0.01 \\
Being subject of potential injuries & - & - & $-0.30^{* * *}$ & $-0.08^{*}$ \\
Experiencing an intense fear & - & -0.04 & $-0.18^{*}$ \\
Having a physical contact with the robber & - & - & - & -0.02 \\
Loss of confidence & - & - & - & -0.01 \\
Anxiety & - & - & - & $0.40^{* * *}$ \\
Dysphoria & - & - & $0.16^{* * *}$ \\
$R^{2}$ & 0.00 & $0.03^{* * *}$ & $0.13^{* * *}$ \\
$\Delta R^{2}$ & - & $0.03^{* * *}$ & $0.10^{* * * *}$ \\
\hline
\end{tabular}

Notes: ${ }^{* P}<0.05 ; * * P<0.01$; ${ }^{* *} * P<0.001$. $R^{2}$ is coefficient of determination. $\Delta R^{2}$ is the change in $R^{2}$ values from one model to another. Variables tested as predictors in the blocks: Block I, pretrauma (demographics); Block 2, peritrauma (proximity/familiarity with the robbery); Block 3, peritrauma (perceived fear of harm and helplessness); Block 4, posttrauma (mental health problems measured by the GHQ-12).

Abbreviation: GHQ-12, General Health Questionnaire-12.

\section{Results}

Different statistical analyses were conducted. First, the descriptives of the single questions related to the bank robbery were calculated: $74 \%(n=478)$ of the sample was directly involved in the robbery; $62 \%(\mathrm{n}=400)$ had already experienced a robbery in the past; $83 \%(n=534)$ were in the same room as the robber; $55 \%(\mathrm{n}=354)$ felt threatened by the robber; $46 \%(\mathrm{n}=299)$ thought they would be hurt; and 58\% $(n=374)$ felt very scared and helpless, while 20\% $(n=130)$ had physical contact with the robber. Finally, in order to show the completeness of the data collected, company records consulted indicated that only $2 \%(n=10)$ of victims of robberies had been injured.

As far as the first regression model is concerned, statistical analyses showed that demographics (age and sex) are not significant in the prediction of trauma. As far as the peritrauma variables are concerned, having already been robbed and being in the same room of the thief were not significant, whereas being directly involved in the robbery, having had thoughts of being hurt, and having perceived intense fear were significant. Finally, GHQ factors were associated with the development of the trauma. Only loss of confidence was not significant (Table 2). Specifically, in the first block, demographic data were not significant. When the peritrauma variables were added in the second and third block, the model was significant, and these dimensions each accounted for the $5 \%$ increase in variance in the second (proximity/familiarity with the robbery) and a further $22 \%$ in the third block (fear of harm and helplessness). Finally, when GHQ dimensions were added in the fourth block, the model was significant, and these dimensions accounted for the $28 \%$ increase in variance.

Overall, the final model of four blocks explains $55 \%$ of the variance for the development of posttraumatic symptoms (Table 2).

In the second regression analysis, we kept the same independent variables divided into four blocks, and we considered avoidance as the dependent variable. Analysis showed that demographic data were not significant. Adding the variables of the second block, being directly involved in the robbery was significant; however, when adding the third and the fourth blocks of variables, a direct involvement in the robbery lost significance. The statistically significant variables in the model were thinking about being injured, having experienced intense fear, anxiety, and depression (GHQ-12). Overall, the final model explains $30 \%$ of the variance for the development of symptoms of avoidance (Table 3 ).

In the third regression analysis, we considered arousal as a dependent variable, in association with the same independent variables of the previous analysis. In this case, demographic data were also not significant, and statistical significance in the second and third block pertained to the following peritraumatic variables: being directly involved in the robbery, having had thoughts of being injured, and having experienced an intense fear. However, in the fourth block, having experienced an intense fear alone remained significant. In addition, anxiety, dysphoria, and loss of confidence resulted as significant and increased the explained variance of $33 \%$ over and above demographics and the peritraumatic variables. Surprisingly, loss of confidence was associated 
Table 4 Hierarchical regression with arousal as criterion variable

\begin{tabular}{|c|c|c|c|c|}
\hline \multirow[t]{2}{*}{ Predictors } & \multicolumn{4}{|l|}{ Arousal } \\
\hline & Block I & Block 2 & Block 3 & Block 4 \\
\hline Sex & 0.03 & 0.05 & 0.04 & 0.00 \\
\hline Age & 0.03 & 0.04 & 0.02 & 0.00 \\
\hline Involvement in the robbery & - & $-0.18 * * *$ & $-0.08 *$ & -0.03 \\
\hline Being already robbed & - & -0.01 & -0.01 & -0.02 \\
\hline Being in the same room of robber & - & 0.00 & -0.00 & 0.00 \\
\hline Being threatened by the robber & - & - & -0.03 & 0.00 \\
\hline Being subject of potential injuries & - & - & $-0.13^{* *}$ & $-0.05^{*}$ \\
\hline Experiencing an intense fear & - & - & $-0.36 * * *$ & $-0.17^{* * *}$ \\
\hline Having a physical contact with the robber & - & - & -0.00 & 0.03 \\
\hline Loss of confidence & - & - & - & $-0.07^{*}$ \\
\hline Anxiety & - & - & - & $0.55 * * *$ \\
\hline Dysphoria & - & - & - & $0.16 * * *$ \\
\hline$R^{2}$ & 0.00 & $0.03 * * *$ & $0.21 * * *$ & $0.54 * * *$ \\
\hline$\Delta R^{2}$ & - & $0.03 * * *$ & $0.18 * * *$ & $0.33 * * *$ \\
\hline
\end{tabular}

Notes: $* P<0.05 ; * * P<0.01 ; * * * P<0.001 . R^{2}$ is coefficient of determination. $\Delta R^{2}$ is the change in $R^{2}$ values from one model to another. Variables tested as predictors in the blocks: Block I, pretrauma (demographics); Block 2, peritrauma (proximity/familiarity with the robbery); Block 3, peritrauma (perceived fear of harm and helplessness); Block 4, posttrauma (mental health problems measured by the GHQ-I2).

Abbreviation: GHQ-12, General Health Questionnaire-12.

negatively with arousal. Overall, the final model explains $54 \%$ of the variance for the development of typical symptoms of arousal (Table 4).

In the final regression analysis, we considered intrusion as the dependent variable. As with arousal, demographic data were not significant, while the significance was being directly involved in the robbery, to having had thoughts about being injured and to having felt an intense fear. Adding the variables of the last block indicated that the significance of the previous blocks did not change and, in addition, anxiety resulted as significant. Overall, the final model explains $48.3 \%$ of the variance for the development of typical symptoms of intrusion (Table 5).

\section{Discussion and conclusion}

The purpose of this study was to examine, among Italian employees, the role of pre-, peri-, and posttrauma variables on PTSD development. The four regression models performed in this study seemed predictive. Based on the $30 \%-55 \%$ of the variance of PTSD and based on these models, PTSD subfactors were explained in our study (intrusion, avoidance, and arousal).

A closer analysis of the specific contribution of each pre-, peri-, and posttrauma variable in the development of PTSD symptomatology showed interesting results. First, pretrauma variables, sex and age, did not seem very connected to the development of the PTSD. Indeed, the impact

Table 5 Hierarchical regression with intrusion as criterion variable

\begin{tabular}{lllll}
\hline Predictors & Intrusion & & Block 3 \\
\cline { 2 - 5 } & Block I & Block 2 & 0.04 & Block 4 \\
\hline Sex & 0.02 & 0.05 & -0.02 & 0.01 \\
Age & -0.02 & -0.01 & $-0.18^{* * *}$ & -0.04 \\
Involvement in the robbery & - & $-0.22^{* * *}$ & 0.04 & $-0.08^{*}$ \\
Being already robbed & - & -0.03 & -0.04 & 0.04 \\
Being in the same room of robber & - & 0.03 & -0.03 & 0.05 \\
Being threatened by the robber & - & - & $-0.21^{* *}$ & 0.00 \\
Being subject of potential injuries & - & $-0.33^{* * *}$ & $-0.15^{* * *}$ \\
Experiencing an intense fear & - & - & 0.02 & $-0.18^{* * *}$ \\
Having a physical contact with the robber & - & - & - & 0.05 \\
Loss of confidence & - & - & - & $0.07^{*}$ \\
Anxiety & - & - & - & $0.25^{* * * *}$ \\
Dysphoria & - & - & $0.05^{* * *}$ & $0.20^{* * *}$ \\
$R^{2}$ & 0.00 & $0.05^{* * *}$ & $0.44^{* * *}$ \\
$\Delta R^{2}$ & - & & $0.19^{* * *}$ \\
\hline
\end{tabular}

Notes: $* P<0.05 ; * * P<0.01 ; * * * P<0.001 . R^{2}$ is coefficient of determination. $\Delta R^{2}$ is the change in $R^{2}$ values from one model to another. Variables tested as predictors in the blocks: Block I, pretrauma (demographics); Block 2, peritrauma (proximity/familiarity with the robbery); Block 3, peritrauma (perceived fear of harm and helplessness); Block 4, posttrauma (mental health problems measured by the GHQ-12).

Abbreviation: GHQ-12, General Health Questionnaire-12. 
of demographics in all models tested was very limited and not significant. Although several studies accounted for sex differences in PTSD, ${ }^{24}$ in our research, variables such as sex and age were not significant following the results of studies conducted on victims of violence (workplace bullying). ${ }^{25-27}$ Furthermore, the origin of sex differences in PTSD may be closely linked to sex differences in the subjective experience and evaluation of the trauma, rather than more objective features, such as trauma type and degree of exposure. ${ }^{24}$

Second, for peritrauma variables in all tested models, higher associations with PTSD symptoms were found, particularly whether he/she felt threatened by the robber, whether he/she imagined potentially being harmed, and whether he/ she felt intense fear.

Finally, GHQ-12 influenced consistently on PTSD symptoms, especially anxiety and depression factors. Loss of confidence was not associated with PTSD; however, as far as intrusion and arousal were concerned, loss of confidence was linked negatively to PTSD symptoms. This may possibly be because self-confident employees might perceive the traumatic experience as more destabilizing than employees with lower positivity. However, the impact of self-confidence on PTSD seemed quite limited, especially when compared with the effects of anxiety and depression (GHQ-12 factors) that could develop in their chronic manifestations, causing an inability to reconcile a traumatic experience with an integrated vision of oneself and the world. People affected also display repeated conscious intrusions of painful memories, followed by a strong physiological activation related to active and passive attempts to avoid the resurfacing of those memories. This cycle of intrusion and avoidance opens the door to a progressive deterioration of symptoms and disabilities in the period following the exposure to traumatic events, even more so in those who are not completely healthy from a mental standpoint.

Since it is so important to prevent and counteract the negative effects of robbery traumas among employees, it has become increasingly relevant to study the psychological antecedents of PTSD.

Our study not only confirms that a bank robbery is a traumatic event for the employee, but also highlights the importance of considering the influence of the individual characteristics of the victim and their immediate reactions on posttraumatic symptomatology. ${ }^{15-20}$ While personal characteristics (sex and age) and the characteristics of the event itself do not seem to have a crucial role, mental health problems seem to have a fundamental role in influencing the development of posttraumatic symptoms over and above pre- and peritrauma variables. As far as peritrauma variables are concerned, intense fear, accompanied by a strong sense of powerlessness, the threat to their own and others' safety felt during the robbery, and the presence of anxiety seem the main risk factors for the development of posttraumatic symptoms. This consideration reinforces our opinion, also supported by the literature of the importance of the victim's personal interpretation with respect to the degree of threat in a robbery at the moment in which it occurs: there are many factors that affect this assessment and not all have a relationship with the objective gravity of the event. ${ }^{18,28}$ The role of mental health is also fundamental.

However, some limitations should be addressed. The first limitation of this study is that it cannot prove causality since the study design was cross-sectional. Consequently, the use of a longitudinal design is suggested. A second limitation is the use of self-reports, which may contribute to common method bias. ${ }^{29} \mathrm{~A}$ third limitation concerns the sample, which is not representative of the Italian population; indeed regions have been exclusively used for purposes of description of the sample.

Unlike other demographic characteristics, such as female sex or age below 25 years, all of which were shown to be unimportant, we underline instead the relevance of preexisting psychopathological disorders as predictors of PTSD. This study definitely deserves follow-up to reach its assigned purpose, namely, to minimize the risk to the employees of a given occupation when they are exposed to a criminal event like a robbery.

Our findings suggest that banks should adopt corporate policies containing activities of prevention and protection toward stress and, more generally, mental health of workers. For example, the availability of a specific policy for bank robberies offers both the company and the workers important tools for well-being, including postrobbery psychological support, online/phone counseling center, training groups, etc.

\section{Disclosure}

The authors report no conflicts of interest in this work.

\section{References}

1. Research Centre for Anti-Crime Security (OSSIF). Report on robberies in bank branches in 2012. Italian Banking Association (ABI), 2013. Available from: http://www.ossif.it/public/pagine/95/201/rapportointersettoriale.2013.pdf. Accessed April 30, 2015.

2. Giorgi G, Arcangeli G, Mucci N, Cupelli V. Economic stress in workplace: the impact of fear the crisis on mental health. Work. 2014. Epub ahead of print. doi:10.3233/WOR-141844.

3. Mucci N, Giorgi G, Cupelli V, et al. Work-related stress assessment in a population of Italian workers. The Stress Questionnaire. Sci Total Environ. 2015;502:673-679. 
4. Giorgi G, Fiz Perez FS, Castiello D'Antonio A, et al. Psychometric properties of the Impact of Event Scale-6 in a sample of victims of bank robbery. Psychol Res Behav Manag. 2015;8:99-104.

5. Miller-Burke J, Attridge M, Fass PM. Impact of traumatic events and organizational response. A study of bank robberies. J Occup Environ Med. 1999;41(2):73-83.

6. Hansen M, Armour C, Elklit A. Assessing a dysphoric arousal model of acute stress disorder symptoms in a clinical sample of rape and bank robbery victims. Eur J Psychotraumatol. Epub 2012 June 12.

7. Carlson EB, Dalemberg CJ. A conceptual framework for the impact of traumatic experiences. Trauma Violence Abuse. 2000;1(1):4-28.

8. Kamphuis JH, Emmelkamp PM. Crime-related trauma: psychological distress in victims of bank robbery. J Anxiety Disord. 1998; 12(3):199-208.

9. Kessler RC, Sonnega A, Bromet E, Hughes M, Nelson CB. Posttraumatic stress disorder in the National Comorbidity Survey. Arch Gen Psychiatry. 1995;52(12):1048-1060.

10. Giorgi G, Leon-Perez JM, Cupelli V, Mucci N, Arcangeli G. Do I just look stressed or am I stressed? Work-related stress in a sample of Italian employees. Ind Health. 2014;52(1):43-53.

11. Belleville G, Marchand A, St-Hilaire MH, Martin M, Silva C. PTSD and depression following armed robbery: patterns of appearance and impact on absenteeism and use of health care services. J Trauma Stress. 2012;25(4):465-468.

12. Hansen M, Elklit A. Predictors of acute stress disorder in response to bank robbery. Eur J Psychotraumatol. Epub 2011 May 12. doi:10.3402/ ejpt.v2i0.5864.

13. Lilly MM, Pierce HA. PTSD and depressive symptoms in 911 telecommunicators: the role of peritraumatic distress and world assumptions in predicting risk. Psychol Trauma. 2013;5(2):135-141.

14. Rutter LA, Weatherrill RP, Krill SC, Orazem R, Taft CT. Postraumatic stress disorder symptoms, depressive symptoms, exercise, and health in college students. Psychol Trauma. 2013;5(1):56-61.

15. Ozer EJ, Best SR, Lipsey TL, Weiss DS. Predictors of posttraumatic stress disorder and symptoms in adults: a meta-analysis. Psychol Bull. 2003;129(1):52-73.

16. Kleim B, Ehlers A, Glucksman E. Early predictors of chronic posttraumatic stress disorder in assault survivors. Psychol Med. 2007; 37(10):1457-1467.

17. Hansen M, Armour C, Shevlin M, Elklit A. Investigating the psychological impact of bank robbery: a cohort study. J Anxiety Disord. 2014; 28(5):454-459.
18. Pacheco-Unguetti AP, Acosta A, Lupiáñez J. Recognizing the bank robber and spotting the difference: emotional state and global vs local attentional set. Span J Psychol. 2014;17:E28.

19. Hansen M, Lasgaard M, Elklit A. The latent factor structure of acute stress disorder following bank robbery: testing alternative models in light of the pending DSM-5. Br J Clin Psychol. 2013;52(1):82-91.

20. Weiss DS, Marmar CR. The impact of event scale-revised. In: Wilson JP, Keane TM, editors. Assessing Psychological Trauma and PTSD. New York: Guilford Press; 1997:399-411.

21. Pietrantonio F, De Gennaro L, Di Paolo MC, Solano L. The impact of event scale: validation of an Italian version. J Psychosom Res. 2003;55(4):389-393.

22. Piccinelli M, Bisoffi G, Bon MG, Cunico L, Tansella M. Validity and test-retest reliability of the Italian version of the 12-item General Health Questionnaire in general practice: a comparison between three scoring methods. Compr Psychiatry. 1993;34(3):198-205.

23. Giorgi G, Leon Perez JM, Castiello D'Antonio A, et al. The General Health Questionnaire (GHQ-12) in a sample of Italian workers: mental health at individual and organizational level. World J Med Sci. 2014;11(1):47-56.

24. Christiansen DM, Hansen M. Accounting for sex differences in PTSD: a multi-variable mediation model. Eur J Psychotraumatol. 2015. doi:10. 3402/ejpt.v6.26068.

25. Giorgi G, Ando M, Arenas A. Exploring personal and organizational determinants of workplace bullying and its prevalence in a Japanese sample. Psychol Viol. 2013;3(2):185-197.

26. Arcangeli G, Giorgi G, Ferrero C, et al. Prevalence of workplace bullying in a population of nurses at three Italian hospitals. G Ital Med Lav Ergon. 2014;36(3):181-185.

27. Giorgi G, Mancuso S, Fiz Perez F, et al. Bullying among nurses and its relationship with burnout and organizational climate. Int J Nurs Pract. 2015. doi:10.1111/ijn.12376.

28. Yule W. Post-traumatic Stress Disorders: Concepts and Therapy. New York: Wiley; 1999.

29. Spector PE. Using self-report questionnaires in OB research: a comment on the use of a controversial method. J Organiz Behav. 1994; 15:385-392.
Neuropsychiatric Disease and Treatment

\section{Publish your work in this journal}

Neuropsychiatric Disease and Treatment is an international, peerreviewed journal of clinical therapeutics and pharmacology focusing on concise rapid reporting of clinical or pre-clinical studies on a range of neuropsychiatric and neurological disorders. This journal is indexed on PubMed Central, the 'PsycINFO' database and CAS,

\section{Dovepress}

and is the official journal of The International Neuropsychiatric Association (INA). The manuscript management system is completely online and includes a very quick and fair peer-review system, which is all easy to use. Visit http://www.dovepress.com/testimonials.php to read real quotes from published authors. 